Article

\title{
Antimicrobial Susceptibility Profiles among Pseudomonas aeruginosa Isolated from Professional SCUBA Divers with Otitis Externa, Swimming Pools and the Ocean at a Diving Operation in South Africa
}

\author{
Kevin Maclean, Fernande Olpa J Pankendem Njamo, Mahloro Hope Serepa-Dlamini (D), Kulsum Kondiah *(D) \\ and Ezekiel Green (D)
}

Citation: Maclean, K.; Njamo, F.O.J.P.; Serepa-Dlamini, M.H.; Kondiah, K.;

Green, E. Antimicrobial Susceptibility Profiles among Pseudomonas aeruginosa Isolated from Professional SCUBA Divers with Otitis Externa, Swimming Pools and the Ocean at a Diving Operation in South Africa.

Pathogens 2022, 11, 91. https://

doi.org/10.3390/pathogens11010091

Academic Editor: Lawrence S.

Young

Received: 23 November 2021

Accepted: 7 January 2022

Published: 13 January 2022

Publisher's Note: MDPI stays neutral with regard to jurisdictional claims in published maps and institutional affiliations.

Copyright: (C) 2022 by the authors. Licensee MDPI, Basel, Switzerland. This article is an open access article distributed under the terms and conditions of the Creative Commons Attribution (CC BY) license (https:// creativecommons.org/licenses/by/ $4.0 /)$.

\author{
Department of Biotechnology and Food Technology, Faculty of Science, Doornfontein Campus, University of \\ Johannesburg, Doornfontein 2028, Johannesburg P.O. Box 17011, South Africa; kevinm@uj.ac.za (K.M.); \\ 218026023@student.uj.ac.za (F.O.J.P.N.); hopes@uj.ac.za (M.H.S.-D.); egreen@uj.ac.za (E.G.) \\ * Correspondence: kulsumk@uj.ac.za; Tel.: +27-11-559-6120
}

\begin{abstract}
SCUBA divers are predisposed to otitis externa caused by Pseudomonas aeruginosa, which is becoming increasingly multi-drug resistant (MDR). The present work assessed the antibiotic resistance profiles of P. aeruginosa obtained from SCUBA divers and their environment in Sodwana Bay, South Africa. Bacterial isolates from a total of 137 random water and ear swab samples were identified using biochemical and molecular methods. P. aeruginosa strains were further evaluated for antibiotic susceptibility using the Kirby-Bauer assay. Double disk synergy test (DDST) to confirm metallo- $\beta$-lactamase (MBL) production and PCR amplification of specific antibiotic resistance genes was performed. All (100\%) 22 P. aeruginosa isolates recovered were resistant to 6 of the $\beta$-lactams tested including imipenem but exhibited susceptibility to trimethoprim-sulfamethoxazole. MBL production was observed in $77 \%$ of isolates while the most prevalent extended-spectrum $\beta$-lactamase (ESBL) genes present included $b l_{A m p C}(86.9 \%)$ followed by $b l a_{T E M}(82.6 \%)$. Sulfonamide resistance was largely encoded by sul1 (63.6\%) and sul2 (77.3\%) genes with a high abundance of class 1 integrons (77.3\%) of which $18.2 \%$ carried both Intl1 and Intl2. P. aeruginosa found in Sodwana Bay exhibits multi-drug resistance (MDRce) to several pharmaceutically important drugs with the potential to transfer antibiotic resistance to other bacteria if the judicious use of antibiotics for their treatment is not practiced.
\end{abstract}

Keywords: antimicrobial resistance; beta lactamase; divers; otitis externa; swimmer's ear

\section{Introduction}

Swimming and other water activities are popular social recreational activities. Swimming pool water is decontaminated to remove harmful bacteria. Nevertheless, certain persistent bacteria survive in water [1] and are able to infect people who use that water for recreational purposes. Self-contained-underwater-breathing-apparatus (SCUBA) diving is a very common aquatic attraction. Approximately 15 million SCUBA dives are conducted on an annual basis worldwide [2]. SCUBA diving has become part of tourism in South Africa, especially in Sodwana Bay in KwaZulu Natal, South Africa. A previous study conducted between July 2011 and July 2012 indicated that a total of 59,553 dives were conducted by 15,789 divers, which resulted in a total value of USD 404,876.53 in Sodwana Bay [3]. Swimming pool water can be contaminated with micro-organisms from the surroundings including bathers [4], making recreational water a source of infectious diseases such as acute gastrointestinal, cutaneous, and respiratory illnesses caused by several micro-organisms [4].

Members of the genus Pseudomonas are commonly found in the environment, including in $10 \%$ of human stools, and on the skin of some healthy humans [5]. Pseudomonas aeruginosa 
has been implicated in infections of the urinary tract, pneumonia, wound infections, and otitis externa throughout the world [6-8]. Otitis externa (OE, swimmer's ear) is an infection of the outer ear attributable to bacteria resulting in irritation of the mucosa layer. The infection might be aggressive as it can rapidly spread outside the external auditory canal, termed malignant otitis externa. Malignant Otitis Externa is an expansive illness with possible involvement of the base of the skull as well as a threat to life [9]. P. aeruginosa has become the most frequently identified pathogen in the development of malignant otitis externa [10]. However, drug resistance is becoming a serious problem in the treatment of P. aeruginosa.

The development of increased resistance in hospital environments [3], in particular, multidrug-resistance (MDRce), exacerbates anti-pseudomonas chemotherapy. It is clear from literature that $P$. aeruginosa has developed resistance against large families of antimicrobial agents, such as the $\beta$-lactams $[11,12]$. The increasing frequency of drug resistance and MDR P. aeruginosa constitute a risk in antibiotic therapy [11]. The eight types of antibiotics used to treat P. aeruginosa infections include: Aminoglycosides (Gentamicin, Tobramycin, Amikacin), Carbapenems (Imipenem, Meropenem), Cephalosporins (Ceftazidime, Cefepime), Fluoroquinolones (Ciprofloxacin, Levofloxacin), Penicillins with $\beta$-lactamase inhibitors (BLI) (Ticarcillin and Piperacillin in combination with Clavulanic acid or Tazobactam) [12], Monobactams (Aztreonam), Fosfomycin, and Polymyxins (Colistin, Polymyxin B). The WHO listed carbapenem resistant $P$. aeruginosa as a priority pathogen [13]. In the past decade, $P$. aeruginosa has been shown to be increasing in resistance due to the presence of various classes of $\beta$-lactamases, namely, A, B, and D [14], which include both extended-spectrum $\beta$-lactamases (ESBLs) and metallo- $\beta$-lactamases (MBLs). Treatment of MDR P. aeruginosa, therefore, relies on combination therapy frequently combining a $\beta$-lactam with an aminoglycoside, for example, ceftolozane and tazobactam or alternatively imipenem, amikacin, and cefepime among others [15]. The aim of this study was to determine the susceptibility profiles of $P$. aeruginosa isolated from professional SCUBA divers, ocean, and swimming pool water from Sodwana Bay, KwaZulu Natal, South Africa, to different classes of antibiotics.

\section{Results and Discussion}

\subsection{Identification of $P$. aeruginosa}

A total of 22 isolates were identified as P. aeruginosa and 1 as P. putida. From the positively identified $P$. aeruginosa isolates, eight $(36.4 \%)$ were isolated from divers with $\mathrm{OE}(\mathrm{OE})$, one of which was a tourist $\left(\mathrm{T}_{\mathrm{w}} \mathrm{OE}\right)$ and two $(9.1 \%)$ isolates were obtained from divers after their first pool training (APT). A single (4.5\%) isolate was obtained from pool water (PW) before the first pool training while two (9.1\%) were isolated from PW after the first pool training. An additional two (9.1\%) P. aeruginosa were isolated from the PW $24 \mathrm{~h}$ after chlorination. Three isolates (13.6\%) of P. aeruginosa were found in surface samples of ocean water (OSW) and a further four (18.2\%) isolates were identified in ocean water 15 to $20 \mathrm{~m}$ deep (OBW). These results correlate well to some of the natural habitats in which $P$. aeruginosa thrives, i.e., water, and the microbiota found on human skin.

$16 \mathrm{~S}$ rDNA sequencing revealed that all the isolates phenotypically identified as P. aeruginosa shared a $98 \%$ to $100 \%$ similarity to $P$. aeruginosa strains in GenBank. Being ubiquitous [14], it was not a surprise that $P$. aeruginosa was isolated from the different sources sampled. The variable genetic makeup of $P$. aeruginosa makes it possible to colonize many habitats including people. For example, $P$. aeruginosa has been reported as being one of the most prevalent antibiotic resistant pathogens responsible for a wide range of hospital acquired infections in critically ill patients within the intensive care unit [15]. It rarely affects healthy people, yet leads to elevated morbidity and deaths in immunodeficient people [16]. In this study, a total of $45.5 \%$ of the isolates emanated from the divers; a majority of which, as expected, originated from divers that had presented with OE. 


\subsection{Antimicrobial Sensitivity Profiling}

Disk diffusion was used to determine the sensitivity of $22 P$. aeruginosa isolates to different classes of antibiotics that included the $\beta$-lactams, aminoglycosides, quinolones, glycopeptides, and sulfonamides. Table 1 shows the antimicrobial susceptibility profiles of $P$. aeruginosa where resistance to all antibiotics tested was evident except for Bactrim (trimethoprim-sulfamethoxazole) to which all isolates were susceptible. All twenty-two $(100 \%)$ P. aeruginosa isolates were resistant to six of the ten $\beta$-lactams tested including imipenem. Only twelve (54.5\%) isolates exhibited resistance to meropenem. High resistance to $\beta$-lactams was also reported in patient samples collected from a private hospital in Durban, South Africa [17]. Of seventeen P. aeruginosa isolates, $94 \%$ were resistant to aztreonam, $82 \%$ to meropenem and $76 \%$ to piperacillin-tazobactam. In addition, $82 \%$ of these isolates also showed resistance to ciprofloxacin. In addition to the presence of ESBLs and MBLs, resistance was attributed to other mechanisms such as impermeability and/or efflux pumps. A review by Ekwanzala et al. [18] goes on to report that in KwaZulu Natal, the distribution frequency of the various classes of AMR includes 9\% each for tetracyclines, sulfonamides, and carbapenems; $18 \%$ for ESBLs; and 55\% for MDR organisms. Both imipenem and meropenem are $\beta$-lactam antibiotics that play a key role in the medical treatment of $P$. aeruginosa infections due to their demonstrated effectiveness and protection. The resistance of $P$. aeruginosa to these $\beta$-lactams could be mediated by one of two chromosomal mechanisms. The OprD porine is said to promote the internalization of imipenem and some meropenem, but not the assimilation of all $\beta$-lactam. Changes to the composition of OprD and/or a decrease in expression contribute to a decline in imipenem sensitivity [19]. Moreover, OprD changes are related to excess expression of the efflux mechanisms increasing meropenem resistance, and thus such bacteria have a high degree of tolerance to these carbapenems and perhaps other antibiotic types, such as quinolones and aminoglycosides [20]. Carbapenem resistant P. aeruginosa is, thus, usually insensitive to most antibacterial agent types, including polymyxins and tigecycline. Regrettably, elevated levels of toxicity and under optimal bioavailability restrict the use of polymyxins and tigecycline. New treatment strategies such as ceftolozane-tazobactam are, thus, becoming important for the treatment of carbapenem resistant $P$. aeruginosa.

Table 1. Antimicrobial resistance of Pseudomonas aeruginosa isolates from divers, pool, and ocean water to different classes of antibiotics.

\begin{tabular}{|c|c|c|c|}
\hline \multirow{2}{*}{ Antibiotics } & \multirow{2}{*}{ Abbreviation } & \multicolumn{2}{|c|}{$\begin{array}{l}\text { Total Number of Resistant Isolates } \\
\qquad n=22\end{array}$} \\
\hline & & $\begin{array}{c}\text { S } \\
\text { No. }(\%)\end{array}$ & $\begin{array}{c}\text { R } \\
\text { No. }(\%)\end{array}$ \\
\hline \multicolumn{4}{|l|}{$\beta$-lactams } \\
\hline Cefotaxime & $c f x$ & $0(0)$ & $22(100)$ \\
\hline Cefaperazone & $c f p$ & $2(9.1)$ & $20(90.9)$ \\
\hline Ceftazidime & $c a z$ & $6(227.3)$ & $16(72.7)$ \\
\hline Meropenem & mem & $10(45.5)$ & $12(54.5)$ \\
\hline Amoxicillin & $a m x$ & $0(0)$ & $22(100)$ \\
\hline Augmentin & $a m c$ & $0(0)$ & $22(100)$ \\
\hline Aztreonam & atm & $4(18.2)$ & $18(81.8)$ \\
\hline Imipenem & $i p m$ & $0(0)$ & $22(100)$ \\
\hline Piperacillin-Tazobactam & $t z p$ & $0(0)$ & $22(100)$ \\
\hline Penicillin G & pen & $0(0)$ & $22(100)$ \\
\hline \multicolumn{4}{|l|}{ Non $\beta$-lactams } \\
\hline Neomycin & neo & $10(45.5)$ & $12(54.5)$ \\
\hline Ciprofloxacin & cip & $0(0)$ & $22(100)$ \\
\hline Amikacin & amk & $0(0)$ & $22(100)$ \\
\hline Polymyxin B & $p m b$ & $15(68.2)$ & $7(31.8)$ \\
\hline Ofloxacin & of $x$ & $0(0)$ & $22(100)$ \\
\hline $\begin{array}{c}\text { Bactrim } \\
\text { (Trimethoprim-sulfamethoxazole) }\end{array}$ & $s x t$ & $22(100)$ & $0(0)$ \\
\hline
\end{tabular}


Interestingly, all 22 isolates were susceptible to Bactrim although $P$. aeruginosa is known to use drug efflux to resist trimethoprim-sulfamethoxazole. Studies in livestock [21] or their products [22] have recorded some susceptibility of $P$. aeruginosa isolates to trimethoprimsulfamethoxazole. Susceptibility to trimethoprim-sulfamethoxazole was also reported in P. aeruginosa isolated from patients with cystic fibrosis [23]. While majority of the susceptible isolates emanated from patients with cystic fibrosis (an increase of 34 to 68\% from 1999 to 2011), a number were also present in non-cystic fibrosis patients. The susceptibility to trimethoprim-sulfamethoxazole was attributed to mutations in mex gene determinants, and in $m u t L$ and mutS. A similar characterization of critical mutations in mexR, mexAB-oprM, mexZ, and mut genes would confirm the sensitivity of the P. aeruginosa isolates in the present study to Bactrim.

\subsection{Detection of ESBL and MBL Production}

Positive DDST results for MBL production were observed from 17 (77\%) of the 22 isolates tested. Infections resulting from MDR $P$. aeruginosa are usually treated with carbapenems, but the increase in MBL prevalence has made its treatment with this class of last line antibiotics increasingly challenging. The added MDRce, evident even in the isolates from this study, further exacerbates the challenges associated with its treatment. MBL producing Pseudomonas species continue to be an important organism causing lifethreatening infections, and therefore the use of DDST for routine screening of $P$. aeruginosa associated with OE in SCUBA divers at dive sites is recommended. The findings from this study indicate that in Sodwana Bay, the treatment of OE causing $P$. aeruginosa using the current prescribed antibiotics may not be effective in clearing the infections. This may be the case at other dive sites both nationally and globally. Sending samples to the laboratory for PCR testing to confirm MDRce in the causative agents would incur higher costs and increase diagnosis time, which would deter recreational SCUBA divers from seeking immediate medical assistance. Therefore, DDST can be used as a rapid technique for the preliminary identification of and subsequently appropriate treatment for MDR isolates. While it is hard to foresee the effect of MBL genes in the future of antimicrobial treatment, there is uncertainty that the mainstay antibiotic regimen used to eradicate $P$. aeruginosa infections can be depended on to control infections by this organism. MBL strains have been found to be correlated with a rapid onset of infection and a rapid trajectory towards mortality, [16] an indication of their importance. Moreover, there is the added risk of transfer of MBL genes from P. aeruginosa to other Enterobacteriaceae. While non-MBL-producing carbapenem-resistant $P$. aeruginosa is not common, such isolates were identified in $22.7 \%$ of the isolates in this study.

The treatment of $P$. aeruginosa is becoming increasingly complex, particularly in hospital situations, because of the inherent and developed resistance to most treatments. In the present study, the $b l a_{A m p C}$ genes were found in $20(86.9 \%), b l a_{T E M}$ in $19(82.6 \%), b l a_{O x a-4}$ in $4(18.2 \%), C T X-M 1$ in 17 (73.9\%), and bla $a_{S H V}$ in 14 (64\%) P. aeruginosa tested, confirming ESBL production (Figure 1). The single P. putida isolate (OSW2) was found to carry bla $a_{A m p C}$, $b l a_{T E M}$, and CTX-M1 genes. All the isolates from this study carried at least two resistance genes responsible for ESBL production (Table 2). Shakibaie et al. reported that $6.6 \%$ and $2.5 \%$ of ESBL-producing $P$. aeruginosa isolates carried $b l a_{S H V}$, and $b l a_{T E M}$ family genes, respectively [24]. CTX-M family members are also known to hydrolyze cefotaxime and ceftriaxone [25]. In South America, Europe, as well as Asia, the CTX-M 1 is most frequently reported $[25,26]$ in E. coli isolates. Notably, the majority of the P. aeruginosa isolates in the study were ESBL strains with the co-production of AmpC of which only one from a diver with OE (OE6) did not carry the bla $a_{A m p}$ gene. Cephamycins including cefoxitin and cefotetan, oxyimino-cephalosporins including ceftazidime, cefotaxime, and ceftriaxone, and monobactams such as aztreonam are hydrolyzed by AmpC $\beta$-lactamases [27]. Therefore, the coexistence of ESBLs and AmpC has significant implications in the treatment of these isolates. While molecular methods such as PCR are better suited to the detection of such 
strains, it is suggested that divers can easily be screened using DDST incorporating 4 th generation cephalosporins.
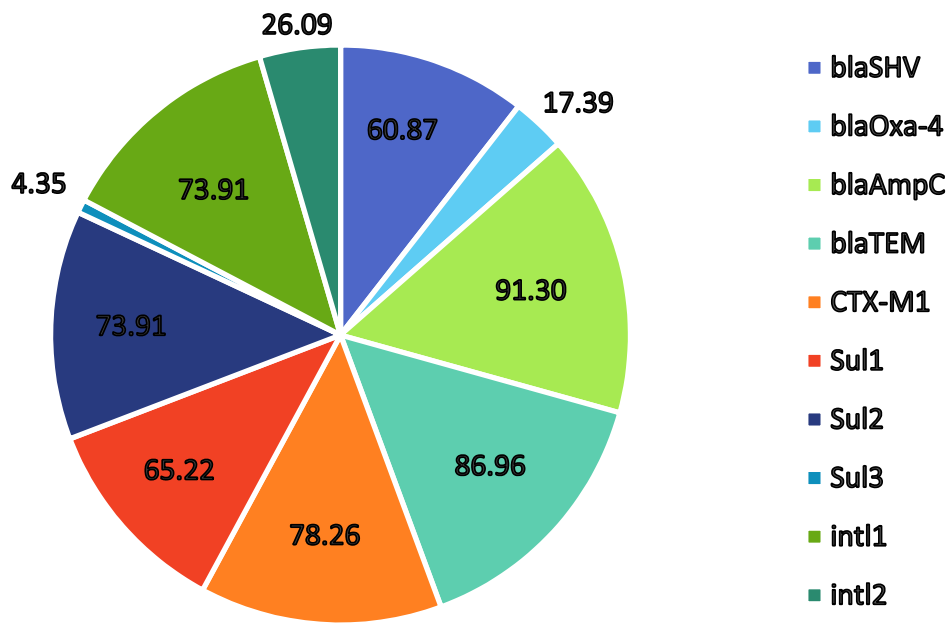

Figure 1. Graphical representation of the \% distribution frequencies of antibiotic resistance genes detected in twenty-three Pseudomonas sp. (22 P. aeruginosa and 1 P. putida) isolated from Sodwana Bay, South Africa.

Table 2. Presence or absence of resistance genes in Pseudomonas aeruginosa isolates.

\begin{tabular}{|c|c|c|c|c|c|c|c|c|c|c|}
\hline \multirow[b]{2}{*}{ Isolate $^{2}$} & \multicolumn{10}{|c|}{ Resistant Gene ${ }^{1}$} \\
\hline & $b l a_{S H V}$ & bla $_{O x a-4}$ & $b^{b l a_{A m p C}}$ & $b l a_{T E M}$ & $C T X-M 1$ & Sul1 & Sul2 & Sul3 & intl1 & intl2 \\
\hline ВРT2 & + & - & - & - & + & - & + & - & - & - \\
\hline APT1 & + & - & + & + & + & + & + & - & + & - \\
\hline APT2 & - & - & + & + & + & + & + & - & - & + \\
\hline ADO1 & + & + & + & + & + & + & - & - & + & - \\
\hline ADO2 & - & - & + & + & + & + & - & - & + & + \\
\hline OE1 & - & - & + & + & + & - & + & - & + & - \\
\hline OE2 & - & + & + & + & + & - & - & - & + & - \\
\hline OE3 & + & - & + & + & + & - & + & - & - & - \\
\hline OE4 & - & - & + & + & + & + & + & - & + & - \\
\hline OE5 & + & - & + & + & + & - & + & - & + & - \\
\hline OE6 & + & - & - & + & + & + & + & - & + & - \\
\hline OE8 & + & - & + & + & - & - & + & - & + & - \\
\hline $\mathrm{T}_{\mathrm{w}} \mathrm{OE} 1$ & + & - & + & + & + & + & + & - & + & - \\
\hline PW1 & + & + & + & - & - & + & - & + & + & + \\
\hline PW2 & - & - & + & + & + & + & + & - & + & - \\
\hline PW3 & + & - & + & + & + & - & - & - & + & + \\
\hline OSW1 & + & + & + & + & - & + & + & - & + & + \\
\hline OSW2 ${ }^{3}$ & - & - & + & + & + & + & + & - & + & - \\
\hline OSW3 & + & - & + & + & + & + & + & - & + & - \\
\hline OBW1 & + & - & + & + & + & + & - & - & - & - \\
\hline OBW2 & + & - & + & - & + & + & + & - & + & - \\
\hline OBW3 & - & - & + & + & - & - & + & - & - & - \\
\hline OBW4 & - & - & + & + & - & + & + & - & - & + \\
\hline
\end{tabular}

${ }^{1}:$ + indicates presence; - indicates absence. ${ }^{2}$ : BPT—before pool training; APT-after pool training; ADOafter ocean dive; $\mathrm{OE}$ - divers with otitis externa; $\mathrm{T}_{\mathrm{W}} \mathrm{OE}$ - tourist diver with otitis externa; $\mathrm{PW}$ - pool water OSW—ocean surface water; OBW—ocean water below $20 \mathrm{~m}^{3}$ : OSW2—identified as P. putida.

\subsection{Presence of Trimethoprim-Sulfonamide-Resistant Genes}

Sulfonamide-resistant genes were found at varied frequencies with sul1 at $63.6 \%$, sul2 at $77.3 \%$, and sul3 at $4.6 \%$ as seen in Figure 1. These findings suggest cause for concern as although all the isolates were susceptible to Bactrim, the presence of the sulfonamide- 
resistant genes in $P$. aeruginosa isolates could result in their transfer within and between other bacterial species present in the same environmental niche. It appears that the most prevalent sul gene in this study was sul2 followed closely by sul1. The resistant gene sul3 was only found in a single isolate PW1. These results correlate with the findings by Suzuki et al. [28] in which sul1 and sul2 were found to be the major genes in total (culturable and non-culturable) bacterial assemblages from aquatic environments in the Durban area of KwaZulu Natal, South Africa. Moreover, their study also reported a low abundance of sul3 in total bacterial assemblages at most sites, which was in contrast to previous studies in the Philippines indicating a high prevalence of sul3 in isolates from seawater.

Interestingly, many of the isolates sharing the same ecological niche showed different resistance patterns such as PW1, PW2, and PW3. Such diversity in the gene pool is likely responsible for the MDRce in these isolates facilitated through horizontal gene transfer (HGT) events. Integrons are genes linked to transposons, plasmids, and chromosomes.

They are responsible in particular for generating antibiotic resistance in pathogenic Gram-negative bacterial infections. Int1l in our study was observed in $17(77.3 \%)$ of the isolates while Intl2 appeared in $6(27.3 \%)$ of the isolates. We observed four $(18.2 \%)$ isolates with both Intl1 and Intl2. Xu et al. [29] were able to detect $2.54 \%$ of P. aeruginosa that contained both Intl1 and Intl2 in hospital patients in China. Only three isolates, BPT2, OBW 1, and OBW3 did not carry either Intl1 or Intl2 genes suggesting the prominent role integrons play in MDRce at Sodwana Bay. Integrons hold a drug resistance gene cassette for various drug groups, and class 1 integrons play a prominent role as a source of resistance genes in both Gram-negative and Gram-positive species. It was therefore not surprising to observe a high abundance of the Intl1 gene in the P. aeruginosa isolates from this study. Of these isolates, $11(50 \%)$ also carried the sul1 gene, which is the most prominent integron in clinical isolates. Irrespective of whether the isolates carried class 1, class 2, or both classes of integrons, all, except isolate PW3, had at least one sul gene present, highlighting the potential for sulfonamide resistance in the future.

\subsection{Correlation between Antibiotic Susceptibility and Resistance Genes}

Few significant relationships were found between the antibiotic resistance phenotypes and the genotypes (presence of antibiotic resistance genes), including that of $\beta$-lactam resistance, despite the high number of resistant isolates seen phenotypically (Table 1). A correlation matrix analysis (Figure 2) of the significant phenotypic antibiotic resistance and genotypes showed few and weak positive relationships between the presence of $\beta$ lactamase genes and resistance to $\beta$-lactams. Only bla $a_{X x-4}$ and $b l a_{A m p C}$ were found to have a weak positive relationship with cefaperazone and meropenem, respectively. The presence of $b l a_{T E M}$ had a predominantly negative relationship with all other genes except for $b l a_{A m p C}$ where it showed a strong positive relationship. Sulfonamide resistance gene, sul3, exhibited a strong positive relationship with $b l a_{O x a-4}$, while sul2 exhibited an equally strong negative relationship with the $\beta$-lactamase gene. The positive relationship of int $l 2$ with $s u l 3, b l a_{O x a-4}$, and $b l a_{A m p C}$ further provides evidence for the prominent role played by integrons in MDRce.

Resistance to meropenem has a negative association with both polymyxin B and cefaperazone, while meropenem and neomycin share a positive relationship. Other significant positive correlations between polymyxin B and cefaperazone also indicate the co-occurrence of resistance, which contributes to MDRce in P. aeruginosa in Sodwana Bay.

An exhaustive profiling of resistance genotypes to different classes of antibiotics is necessary to determine the extent of MDRce in P. aeruginosa. Amplification of, for example, aac(3)-III (aminoglycoside resistance), $q n r A, q n r B, q n r S$ (quinolone resistance), tet (tetracycline resistance), and blaIMP and blaVIM could provide more insight into the antibiotic resistance profiles of the isolates. Additionally, antibiotic resistance due to mutations, rather than the acquisition of antibiotic resistance genes, could be at play here. While the sample size is a limiting factor, this study provides the first evidence of MDR $P$. aeruginosa in Sodwana Bay that results in OE infections in SCUBA divers. 


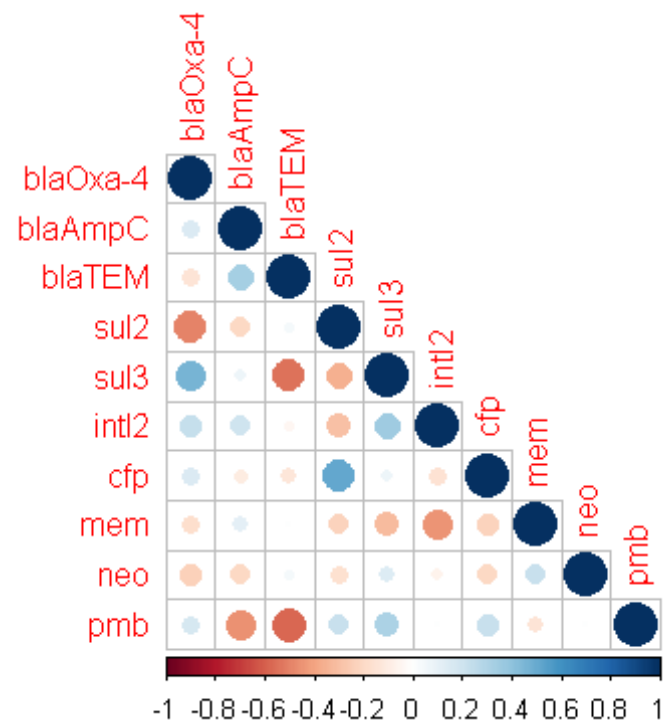

Figure 2. Correlation matrix of antibiotic resistance phenotype and genotypic (antibiotic resistance genes) features showing significant $(p<0.05)$ correlations. Blue circles indicated significant positive correlation and red show significant negative correlation. The size and strength of color represent the numerical value of the correlation coefficient.

\section{Materials and Methods}

\subsection{Ethics Statement}

The study was conducted in accordance with the Declaration of Helsinki and the study protocol was approved by the Ethics Committee of the University of Johannesburg (Reference number 2018-08-06). All participants gave their informed consent for inclusion in the study.

\subsection{Sample Collection}

A total of 137 random samples were collected at Sodwana Bay. These included 22 ear swabs from apprentice divers before pool training (BPT); 19 ear swabs after they completed their pool training (APT); 6 ear swabs from apprentice divers who completed some ocean dives (ADO); and 10 ear swabs from apprentice and professional divers who presented with $\mathrm{OE}(\mathrm{OE})$ including a visiting tourist with $\mathrm{OE}\left(\mathrm{T}_{\mathrm{w}} \mathrm{OE}\right)$. In addition, 10 samples of water were collected from the training pool (PW) and 70 samples of seawater were collected from different surface distances in the vicinity of the dive (OSW), 30 of which were collected at depths between 15 and $22 \mathrm{~m}$ (OBW). The water samples were collected in $1000 \mathrm{~mL}$ sterile pressure resistant Schott bottles. The samples were then placed on ice and transported to the laboratory for further analysis within $24 \mathrm{~h}$.

\subsection{Isolation and Identification of P. aeruginosa}

The ear swabs were incubated in nutrient broth (NB) at $37^{\circ} \mathrm{C}$ for $24 \mathrm{~h}$. After incubation the cultures were streaked onto sterile nutrient agar (NA) plates and Pseudomonas aeruginosa cetrimide agar (PACA) followed by overnight incubation at $37^{\circ} \mathrm{C}$ for $24-48 \mathrm{~h}$ to obtain pure cultures [30]. The water samples were membrane filtered and the impregnated filter paper discs were aseptically placed onto NA and PACA plates followed by incubation at $37^{\circ} \mathrm{C}$ for $24-48 \mathrm{~h}$. Bacterial colonies exhibiting a greenish pigmentation (indicative of P. aeruginosa pyocyanin production) were morphologically confirmed to be Gram-negative bacilli, and further characterized in duplicate using standard biochemical tests: oxidase, catalase, nitrate reduction, indole, methyl red, Voges-Proskauer, citrate utilization, and glucose fermentation tests $[15,16]$.

The isolates were also identified by $16 \mathrm{~S}$ rDNA sequencing using the universal forward primer 16S-27F-AGAGTTTGATCMTGGCTCAG and reverse primer 16S-1492R- CGGT- 
TACCTTGTTACGACTT. Fragments were analysed on an ABI 3500xl Genetic Analyzer (Applied Biosystems, ThermoFisher Scientific) and 16S rDNA sequences aligned to reference bacterial species using Basic Local Alignment Search Tool (BLAST) available at http:/ / www.ncbinlm.nih.gov / (accessed date 23 December 2021) for identification.

\subsection{Antimicrobial Sensitivity Testing}

Antimicrobial susceptibility tests were performed by the disk diffusion method for the 22 isolates confirmed to be $P$. aeruginosa using commercially available antibiotic disks (Manchester, UK) according to the Clinical Laboratory Standard Institute guidelines (2018) (CLSI, 2018). The following antibiotics, which included those generally prescribed by medical practitioners in Sodwana Bay to treat patients with ear infections (possibly OE), were used: $\beta$-lactams: Cefotaxime $30 \mu \mathrm{g}$, Cefaperazone $30 \mu \mathrm{g}$, Ceftazidime $30 \mu \mathrm{g}$, Meropenem $10 \mu \mathrm{g}$, Amoxicillin $30 \mu \mathrm{g}$, Augmentin (Amoxicillin-Clavulanic acid) $30 \mu \mathrm{g}$, Aztreonam $30 \mu \mathrm{g}$, Imipenem $10 \mu \mathrm{g}$, Piperacillin-Tazobactam $36 \mu \mathrm{g}$, Penicillin G $10 \mathrm{U}$; Non $\beta$-lactams: Neomycin $30 \mu \mathrm{g}$, Ciprofloxacin $10 \mu \mathrm{g}$, Amikacin $30 \mu \mathrm{g}$, Polymyxin B $300 \mathrm{U}$, Ofloxacin $5 \mu \mathrm{g}$, and Bactrim (trimethoprim-sulfamethoxazole (1.25/23.75)). P. aeruginosa ATCC 27853 was used as the positive control. Mueller-Hinton agar plates were incubated at $37^{\circ} \mathrm{C}$ for $18 \mathrm{~h}$, after which they were observed for the presence of zones of growth inhibition around the different antibiotic disks [31]. The results were interpreted using the recommendations from the guidelines M26-A and M-100S 27 of the Clinical and Laboratory Standard Institute [31]. Zone diameter breakpoints for $P$. aeruginosa within the different classes of antibiotics used in this study can be found in Supplementary Table S1.

\subsection{Phenotypic Detection of ESBLs and MBLs}

The Double Disk Synergy Test (DDST) was used to detect MBL production in all isolates confirmed to be P. aeruginosa and unaffected by imipenem and/or meropenem. For MBL production, disks comprising imipenem-EDTA were placed on lawn cultures grown on Mueller-Hinton agar plates as recommended by the CLSI. MBL-positive isolates were defined as those with a difference of $\geq 7 \mathrm{~mm}$ in diameter between imipenem-EDTA and imipenem-only disk inhibition [32]. The EDTA disc alone, and strains of $P$. aeruginosa that are positive for VIM-1 MBL production, were used as controls.

\subsection{PCR Detection of Genes Associated with Antimicrobial Resistance}

The prevalence of $\beta$-lactamase genes TEM, SHV, OXA, CTX-M, and AmpC was determined by PCR amplification following the method of Abrar et al. (2019) [33]. Genes, sul1, sul2, and sul3 associated with trimethoprim-sulfonamide resistance were examined in isolates according to Jouini et al. [34]. The presence of IntII and IntI2 genes encoding classes 1 and 2 integrases, respectively, were identified by PCR according to Machado et al. [35]. Positive and negative controls were kindly provided by the University of Johannesburg, Doornfontein, Johannesburg, and were used in all PCR experiments.

\subsection{Statistical Analysis}

Antibiotic susceptibility and resistance gene profiles were converted into a binary coding system for the purpose of statistical analysis. Resistance to an antibiotic was represented as one, while susceptibility was assigned a zero. Similarly, the presence of a specific antibiotic resistance gene was assigned a one, while absence of the gene was assigned a zero. Correlations between the phenotypes and genotypes were calculated using the 'cor' function and the significance (Pearson method) determined using the 'corr.test' function in the open statistical program $\mathrm{R}$ (v4.1.2) [36]. Correlations of significant relationships ( $p$-value of $<0.05$ was considered statistically significant) were further visualized using the 'corrplot' function from the 'corrplot' R package (v0.92) [37]. 


\section{Conclusions}

In our research, the increased rate of ESBLs found in P. aeruginosa isolated from SCUBA divers, swimming pool water, and ocean water in Sodwana Bay, South Africa demonstrated a rise in MDRce, which subsequently impacts the treatment of OE using popular pharmaceuticals such as imipenem. Although all the isolates were found to be susceptible to Bactrim (trimethoprim-sulfamethoxazole), the high prevalence of sul genes and class 1 and 2 integrons suggests the potential for bacteria in these environmental niches to develop resistance to sulfonamides in the future. This will lead to enhanced spread of infection, complexities of clinical conditions, and therapy failures in our institutions.

Supplementary Materials: The following supporting information can be downloaded at: https: / / www.mdpi.com/article/10.3390/pathogens11010091/s1, Table S1: Zone diameter breakpoints to different classes of antibiotics used in this study based on the CLSI guidelines for Pseudomonas aeruginosa [Table 2B-1, 31].

Author Contributions: Conceptualization, K.M., M.H.S.-D., K.K. and E.G.; data curation, K.M., M.H.S.-D., K.K., and E.G.; formal analysis, K.M., M.H.S.-D., K.K. and E.G.; funding acquisition, E.G.; investigation, K.M. and F.O.J.P.N.; methodology, M.H.S.-D., K.K. and E.G.; project administration, E.G.; resources, M.H.S.-D., K.K. and E.G.; software, M.H.S.-D. and K.K.; supervision, M.H.S.-D., K.K. and E.G.; validation, E.G.; visualization, K.K.; writing-original draft, K.M. and F.O.J.P.N.; writing-review and editing, M.H.S.-D., K.K. and E.G. All authors have read and agreed to the published version of the manuscript.

Funding: This research was funded by the South African National Research Foundation, grant number 114384 and The APC was funded by the University of Johannesburg, Faculty of Science.

Institutional Review Board Statement: The study was conducted according to the guidelines of the Declaration of Helsinki and approved by the Ethics Committee of University of Johannesburg (ethical clearance number:2018-08-06/Maclean).

Informed Consent Statement: Informed consent was obtained from all subjects involved in the study. Written informed consent was obtained from the patient(s) to publish this paper.

Data Availability Statement: On request from the principal investigator, the data described in this study will be provided.

Acknowledgments: We would like to thank Lynca Viljoen from the University of Johannesburg for allowing us to use her laboratory for DNA isolation and PCR.

Conflicts of Interest: The authors declare no conflict of interest. The funders had no role in the design of the study; in the collection, analyses, or interpretation of data; in the writing of the manuscript, or in the decision to publish the results.

\section{References}

1. Zhang, Y.; Wang, Q.; Low, W.; Wang, Y.; Zhu, X. Microbiological safety of household membrane water filter. J. Environ. Biol. 2013, 34, 481-487.

2. Azizi, M.H. Ear disorders in Scuba Divers. Int. J. Occup. Environ. Med. 2011, 2, 21.

3. Hlavsa, C.M.; Cikesh, L.B.; Roberts, A.V.; Kahler, M.A.; Vigar, M.; Hilborn, D.E.; Wade, J.T.; Roellig, D.M.; Murphy, L.J.; Xiao, L.; et al. Outbreaks associated with treated recreational water-United States, 2000-2014. Morb. Mortal. Wkly. Rep. 2018, 67, 547-551. [CrossRef]

4. D'Agata, E. Pseudomonas aeruginosa and other pseudomonas species. In Infectious Disease Essentials, 8th ed.; Mandell, E.J., Dolin, R., Blaser, M.J., Eds.; Elsevier: Philadelphia, PA, USA, 2017; pp. 1-561.

5. Geyer, M.; Howell-Jones, R.; Cunningham, R.; McNulty, C. Consensus of microbiology reporting of ear swab results to primary care clinicians in patients with otitis externa. Br. J. Biomed. Sci. 2011, 68, 174-180. [CrossRef]

6. Rossolini, G.M.; Mantengoli, E. Treatment and control of severe infections caused by multi-resistant Pseudomonas aeruginosa. Clin. Microbiol. Infect. 2005, 11, 17-32. [CrossRef] [PubMed]

7. Pillay, D.; Jardine, N.P. Recreational scuba divers knowledge regarding the audiological consequences of the sport. S. Afr. J. Sports Med. 2010, 22, 80-83. [CrossRef]

8. Kumar, S.P.; Singh, U. Malignant otitis externa: A review. J. Infect. Dis. Ther. 2015, 3, 204. [CrossRef]

9. Illing, E.; Olaleye, O. Malignant otitis externa: A review of aetiology, presentation, investigations and current management strategies. Webmed Cent. Otorhinolaryngol. 2011, 2, WMC001725. 
10. Zowalaty, E.E.M.; Thani, A.A.A.; Webster, J.T.; Zowalaty, E.E.A.; Schweizer, P.H.; Nasrallah, N.G.; Marei, H.E.; Ashour, M.H. Pseudomonas aeruginosa: Arsenal of resistance mechanisms, decades of changing resistance profiles, and future antimicrobial therapies. Future Microbiol. 2015, 10, 1683-1706. [CrossRef]

11. Puzniak, L.; De Pestel, D.D.; Srinivasan, A.; Ye, G.; Murray, J.; Merchant, S.; De Ryke, C.A.; Gupta, V. A combination antibiogram evaluation for Pseudomonas aeruginosa in respiratory and blood sources from intensive care unit (ICU) and non-ICU settings in U.S. hospitals. Antimicrob. Agents Chemother. 2019, 63, e02564-18. [CrossRef]

12. Tacconelli, E.; Carrara, E.; Savoldi, A.; Harbarth, S.; Mendelson, M.; Monnet, D.L.; Pulcini, C.; Kahlmeter, G.; Kluytmans, J.; Carmeli, Y.; et al. WHO Pathogens Priority List Working Group. Discovery, research, and development of new antibiotics: The WHO priority list of antibiotic-resistant bacteria and tuberculosis. Lancet Infect. Dis. 2018, 18, 318-327. [CrossRef]

13. Kali, A.; Srirangaraj, S.; Kumar, S.; Divya, H.A.; Kalyani, A.; Umadevi, S. Detection of metallo- $\beta$-lactamase producing Pseudomonas aeruginosa in intensive care units. Aust. Med. J. 2013, 6, 686-693. [CrossRef]

14. Barbier, F.; Andremont, A.; Wolff, M.; Bouadma, L. Hospital-acquired pneumonia and ventilator-associated pneumonia: Recent advances in epidemiology and management. Curr. Opin. Pulm. Med. 2013, 19, 216-228. [CrossRef]

15. Pachori, P.; Gothalwal, R.; Gandhi, P. Emergence of antibiotic resistance Pseudomonas aeruginosa in intensive care unit; a critical review. Genes Dis. 2019, 6, 109-119. [CrossRef]

16. Shu, J.-C.; Kuo, A.-J.; Su, L.-H.; Liu, T.-P.; Lee, M.-H.; Su, I.-N.; Wu, T.-L. Development of carbapenem resistance in Pseudomonas aeruginosa is associated with OprD polymorphisms, particularly the amino acid substitution at codon 170 Antimicrob. Chemother. 2017, 72, 2489-2495. [CrossRef]

17. Adjei, C.B.; Govinden, U.; Moodley, K.; Essack, S.Y. Molecular characterisation of multidrug-resistant Pseudomonas aeruginosa from a private hospital in Durban, South Africa. S. Afr. J. Infect. Dis. 2018, 33, 38-41.

18. Ekwanzala, M.D.; Dewar, J.B.; Kamika, I.; Momba, M.N.B. Systematic review in South Africa reveals antibiotic resistance genes shared between clinical and environmental settings. Infect Drug Resist. 2018, 11, 1907-1920. [CrossRef]

19. Kao, C.-Y.; Chen, S.-S.; Hung, K.-H.H.; Wu, H.-M.; Hsueh, P.-R.; Jing-Jou Yan, J.-J.; Wu, J.-J. Overproduction of active efflux pump and variations of OprD dominate in imipenem resistant Pseudomonas aeruginosa isolated from patients with bloodstream infections in Taiwan. BMC Microbiol. 2016, 16, 107. [CrossRef] [PubMed]

20. Tabar, M.M.; Mirkalantari, S.; Amoli, R.I. Detection of ctx-M gene in ESBL producing E. coli strains isolated from urinary tract infection in Semnan, Iran. Electron. Physician 2016, 8, 2686-26990. [CrossRef] [PubMed]

21. Varriale, L.; Dipineto, L.; Russo, T.P.; Borrelli, L.; Romano, V.; D’Orazio, S.; Pace, A.; Menna, L.F.; Fioretti, A.; Santaniello, A. Antimicrobial resistance of Escherichia coli and Pseudomonas aeruginosa from companion birds. Antibiotics 2020, 9, 780. [CrossRef] [PubMed]

22. Meng, L.; Liu, H.; Lan, T.; Dong, L.; Hu, H.; Zhao, S.; Zhang, Y.; Zheng, N.; Wang, J. Antibiotic resistance patterns of Pseudomonas spp. isolated from raw milk revealed by whole genome sequencing. Front. Microbiol. 2020, 11, 1005. [CrossRef] [PubMed]

23. Qin, X.; Zerr, D.M.; McNutt, M.A.; Berry, J.E.; Burns, J.L.; Kapur, R.P. Pseudomonas aeruginosa syntrophy in chronically colonized airways of cystic fibrosis patients. Antimicrob. Agents Chemother. 2012, 56, 5971. [CrossRef] [PubMed]

24. Shakibaie, M.S.F.; Hashemi, A.; Adeli, S. Detection of TEM, SHV and PER type extended-spectrum beta-lactamase genes among clinical strains of Pseudomonas aeroginosa isolated from burnt patients Shafa hospital, Kerman, Iran. Iran J. Basic Med. Sci. 2008, 11, 104-111.

25. Rossolini, G.M.; D'Andrea, M.M.; Mugnaioli, C. The spread of CTXM-type extended-spectrum beta-lactamases. Clin. Microbiol. Infect. 2008, 14 (Suppl. 1), 33-41. [CrossRef]

26. Dabir, S.; Mohammadi, J.; Alizadeh, A.; Karimi, F.; Nori, K.; Mahmoudi, S.; Pournajafi, A. Investigation of the prevalence of CTX-M-1 beta-lactamase gene in Pseudomonas aeruginosa strains isolated from urinary tract infections in Zanjan Hospitals, Iran. $S$. Asian Res. J. Biol. Appl. Biosci. 2020, 2, 20-24. [CrossRef]

27. Hsieh, W.-S.; Wang, N.-Y.; Feng, J.-A.; Weng, L.-C.; Wu, H.-H. Identification of DHA-23, a novel plasmid-mediated and inducible AmpC beta-lactamase from Enterobacteriaceae in Northern Taiwan. Front. Microbiol. 2015, 6, 436. [CrossRef] [PubMed]

28. Suzuki, S.; Ogo, M.; Koike, T.; Takada, H.; Newman, B. Sulfonamide and tetracycline resistance genes in total and culturable bacterial assemblages in South African aquatic environments. Front. Microbiol. 2015, 6, 796. [CrossRef]

29. Xu, Z.; Li, L.; Shirtliff, M.E.; Alam, M.J.; Yamasaki, S.; Shi, L. Occurrence and characteristics of class 1 and 2 integrons in Pseudomonas aeruginosa isolates from patients in Southern China. J. Clin. Microbiol. 2009, 47, 230-234. [CrossRef]

30. Quinn, P.J.; Markey, B.K.; Leonard, F.C.; Fitz Patrick, E.S.; Fanning, S.; Hartigan, P.J. Veterinary Microbiology and Microbial Diseases, 2nd ed.; Blackwell Publishing Ltd.: Ames, IA, USA, 2011; pp. 287-290.

31. Clinical and Laboratory Standards Institute. Methods for Determining Bactericidal Activity of Antimicrobial Agents Approved Guideline; CLSI Document M100S; CLSI: Malvern, PA, USA, 2017; Volume 27, pp. 42-44.

32. De, S.A.; Kumar, H.S.; Baveja, M.S. Prevalence of metallo- $\beta$-lactamase producing Pseudomonas aeruginosa and Acinetobacter species in intensive care areas in a tertiary care hospital. Indian J. Crit. Care Med. 2010, 14, 217-219. [CrossRef]

33. Abrar, S.; Ain, A.U.; Liaqat, H.; Hussain, S.; Rasheed, F.; Riaz, S. Distribution of blaCTX-M, blaTEM, blaSHV and blaOXA genes in extended-spectrum- $\beta$-lactamase-producing clinical isolates: A three-year multi-center study from Lahore, Pakistan. Antimicrob. Resist. Infect. Control 2019, 8, 80. [CrossRef] 
34. Jouini, A.; Vinué, L.; Slama, K.B.; Sáenz, Y.; Klibi, N.; Hammami, S.; Boudabous, A.; Torres, C. Characterization of CTX-M and SHV extended-spectrum beta-lactamases and associated resistance genes in Escherichia coli strains of food samples in Tunisia. J. Antimicrob. Chemother. 2007, 60, 1137-1141. [CrossRef] [PubMed]

35. Machado, E.; Cantón, R.; Baquero, F.; Galán, J.C.; Rollán, A.; Peixe, L.; Coque, T.M. Integron content of extended-spectrum-betalactamase-producing Escherichia coli strains over 12 years in a single hospital in Madrid, Spain. Antimicrob. Agents Chemother. 2005, 49, 1823-1829. [CrossRef] [PubMed]

36. R Foundation for Statistical Computing; R Core Team. R: A Language and Environment for Statistical Computing; R Foundation for Statistical Computing: Vienna, Austria, 2021. Available online: https:/ / www.R.-project.org/ (accessed on 23 December 2021).

37. Wei, T.; Simko, V. R Package 'Corrplot': Visualization of a Correlation Matrix; R Foundation for Statistical Computing: Vienna, Austria, 2021; Available online: https:/ / github.com/taiyun/corrplot (accessed on 23 December 2021). 